\title{
Comparative analysis of the HTLV-I Rex and HIV-1 Rev trans-regulatory proteins and their RNA response elements
}

\author{
Sarah M. Hanly, Laurence T. Rimsky, Michael H. Malim, Jerome H. Kim, Joachim Hauber, ${ }^{1}$ \\ Madeleine Duc Dodon, ${ }^{2}$ Shu-Yun Le, ${ }^{3}$ Jacob V. Maizel, ${ }^{3}$ Bryan R. Cullen, and Warner C. Greene ${ }^{4}$
}

\begin{abstract}
Howard Hughes Medical Institute and Departments of Medicine and Microbiology-Immunology, Duke University Medical Center, Durham, North Carolina 27710 USA; ${ }^{2}$ Centre National de la Recherche Scientifique, Faculte de Medecine Alexis Carrel, 69372 Lyon Cedex 08, France; ${ }^{3}$ Laboratory of Mathematical Biology, Division of Cancer Biology and Diagnosis, National Cancer Institute, National Institutes of Health, Frederick, Maryland 21701 USA
\end{abstract}

The Rex proteins of types I and II human T-cell leukemia viruses (HTLV-I, HTLV-II) are required for expression of the viral structural gene products, gag and $e n v$ and, thus, are essential for the replication of these pathogenic retroviruses. The action of Rex is sequence specific, requiring the presence of a cis-acting Rex response element located in the 3' long terminal repeat. This element corresponds to a predicted RNA secondary structure and functions in an orientation-dependent but position-independent manner. Rex acts through this response element to stimulate the nuclear export of the unspliced or singly spliced viral mRNA species encoding the virion structural proteins that are normally excluded from the cytoplasm. Although the Rex proteins of HTLV-I and HTLV-II can also function via the related Rev response element present in the env gene of the type I human immunodeficiency virus (HIV-1), the analogous HIV-1 Rev protein is unable to act on the HTLV-I Rex response element. This nonreciprocal pattern of genetic complementation by Rex and Rev suggests that these viral trans-regulators may interact directly with their RNA response elements.

[Key Words: Human retrovirus; gene regulation; RNA transport; RNA secondary structure]

Received July 12, 1989; accepted August 21, 1989.

Type I human T-cell leukemia virus (HTLV-I) has been etiologically linked with adult T-cell leukemia and, more recently, with a progressive demyelinating syndrome resembling multiple sclerosis, termed HTLV-I-associated myelopathy or tropical spastic paraparesis (Poiesz et al. 1980; Poiesz et al. 1981; Hanaoka et al. 1982; Yoshida et al. 1982; Gessain et al. 1985; Osame et al. 1986). The closely related human retrovirus HTLV-II has also been found in certain T-cell tumors, notably $\mathrm{T}$ cell variants of hairy cell leukemia (Kalyanaraman et al. 1982; Chen et al. 1983). Although the precise mechanism for $T$-cell transformation by these viruses has not been elucidated, it seems likely that a novel mechanism is involved, as neither HTLV-I nor HTLV-II contains a viral oncogene nor causes transformation by an insertional mechanism (for review, see Yoshida and Seiki 1987).

As is characteristic of all replication-competent retroviruses, the HTLVs encode functional gag, pol, and env proteins (Burny et al. 1980; Seiki et al. 1983; Sagata et al. 1985; Shimotohno et al. 1984). In addition to these proteins, HTLV-I and HTLV-II encode at least two pX-derived trans-regulatory proteins, termed $\operatorname{Rex}\left(\mathrm{p} 27^{\mathrm{x}-\mathrm{II}}\right)$ and

${ }^{1}$ Current address: Sandoz Research Institute, A1235 Vienna, Austria. ${ }^{4}$ Corresponding author.
$\operatorname{Tax}\left(\mathrm{p}^{4} 0^{\mathrm{x}}\right)$. These proteins are translated in different reading frames from the same doubly spliced mRNA; each is required for viral replication and has been implicated in viral leukemogenesis (for review, see Rosenblatt et al. 1986). The Tax protein is a transcriptional activator that not only augments activity of the HTLV-I long terminal repeat (LTR) (Sodroski et al. 1984a) but also induces the expression of select cellular genes involved in T-cell growth, including interleukin-2 (IL-2) and the $\alpha$-subunit of the IL-2 receptor (Inoue et al. 1986; Wano et al. 1988). In contrast to Tax, the Rex protein acts at a post-trancriptional level, permitting expression of the gag, pol, and env gene products necessary for virion assembly (Inoue et al. 1986, 1987; Hidaka et al. 1988).

The type 1 human immunodeficiency virus (HIV-1) is only distantly related to HTLV-I and HTLV-II and produces cytopathic, rather than immortalizing, effects in human $\mathrm{CD}^{+}{ }^{+} \mathrm{T}$ cells (Siegal et al. 1981; Barre-Sinoussi et al. 1983; Gallo et al. 1984; Popovic et al. 1984; Sarngadharan et al. 1984). Despite these functional and evolutionary differences, HIV-1 also encodes nuclear transactivating proteins, termed Tat and Rev, whose functions are similar to the Tax and Rex proteins of HTLV-I and HTLV-II. (Sodroski et al. 1985, 1986; Fisher et al. 1986; Cullen 1986; Dayton et al. 1986; Feinberg et al. 1986; Sadaie et al. 1988; Terwilliger et al. 1988). We 
have previously demonstrated that the HTLV-I Rex protein is capable of functionally substituting for the HIV-1 Rev protein, as evidenced by the rescue of replication of rev-deficient HIV-1 proviruses (Rimsky et al. 1988). In this report, we show that this unexpected genetic complementation of Rex for Rev is nonreciprocal, as the HIV-1 Rev protein is unable to substitute for the HTLV-I Rex protein. In contrast, the more closely related Rex protein of HTLV-II is able to fully complement the function of the HTLV-I Rex protein. We further define properties of the Rex response element (RexRE) present in the $3^{\prime}$ LTR of HTLV-I. We demonstrate that this element corresponds to a highly ordered, predicted RNA stem-loop structure, acts independently of $3^{\prime}$ mRNA cleavage and polyadenylation, and functions in an orientation-dependent but position-independent manner. Finally, we demonstrate that Rex, like Rev, acts, at least in part, by inducing the nucleocytoplasmic transport of the unspliced viral RNA species. Rex thus permits the expression of the viral structural proteins which, in turn, allows for the assembly of infectious virions.

\section{Results}

HTLV-I and HTLV-II Rex but not HIV-1 Rev, induce $H T L V-I$ env gene expression

To analyze Rex-induced expression of the HTLV-I envelope protein and the cis-acting sequences involved in this response, two HTLV-I reporter plasmids, termed pgTAX and pgTAX-LTR, were prepared. Both of these vectors contain the two coding exons for tax, separated by an intron corresponding to the coding region of the HTLV-I env gene (see Fig. 1A). Fully spliced mRNAs produced by these vectors, using the indicated splice donor and acceptor sites, encode the $40-\mathrm{kD}$ Tax protein. In contrast, unspliced mRNAs encode the 62 -kD HTLVI envelope precursor protein. Signals required for accurate mRNA 3 '-end formation and polyadenylation are provided in the pgTAX vector by a fragment from the rat preproinsulin II gene (Cullen 1986). Like pgTAX, the pgTAX-LTR reporter plasmid contains coding sequences for the Tax and envelope proteins. However, this vector also contains the complete HTLV-I 3' LTR, including a region previously implicated in Rex responsiveness (Seiki et al. 1988) and viral signals mediating polyadenylation.

COS cells were transiently cotransfected with the pgTAX or pgTAX-LTR plasmids and either Rex-I (pcREX, Rimsky et al. 1988), Rex-II (pgREX-II, J.H. Kim et al., unpubl.), or Rev (Malim et al. 1988) expression vectors, or a control IL-2 expression vector (pBC12/ CMV/IL-2, Cullen 1986). After $60 \mathrm{hr}$ of culture, the cells were labeled metabolically with $\left[{ }^{35} S\right]$ cysteine, and expression of HTLV-I Tax and envelope proteins was monitored by immunoprecipitation of the radiolabeled cell extracts with antibodies specific for these proteins (Matsushita et al. 1986; Rimsky et al. 1988). Cells cotransfected with the pgTAX expression vector in combination with $\mathrm{pBC} 12 / \mathrm{CMV} / \mathrm{IL}-2$, pcREX-1, pgREX-II, or pcREV expressed the $40-\mathrm{kD}$ Tax protein (Fig. 1B, lanes 5-8) but lacked detectable envelope protein production (Fig. 1C, lanes 5-8). In contrast, when COS cells were cotransfected with the pgTAX-LTR vector in the presence of Rex-I or Rex-II, but not Rev, HTLV-I env gene expression was readily detected (Fig. 1C, lanes 2-4). These findings both confirm the presence of a RexRE in the 3' LTR and reveal that Rex-I and Rex-II, but not Rev, can act on this cis-regulatory sequence.

\section{HTLV-I Rex complementation of HIV-1 Rev activity involves the same HIV-1 regulatory sequence}

Recently, a cis-regulatory sequence was identified in the HIV-1 genome that is required for HIV-1 Rev action (Rosen et al. 1988; Felber et al. 1989; Hadzopoulou-Cladaras et al. 1989; Hammarskjold et al. 1989; Malim et al. 1989). Unlike the HTLV-I RexRE that is located in the $3^{\prime}$ LTR, the HIV-1 Rev response element (RevRE) lies in the intronic env region separating the two tat-coding exons (see Fig. 2A and Malim et al. 1989). This RevRE corresponds to a highly ordered predicted secondary structure within the viral RNA (Malim et al. 1989). Because the HTLV-I Rex protein can functionally replace the HIV-1 Rev protein (Rimsky et al. 1988), we investigated whether these effects of Rex are mediated through the HIV-1 RevRE.

For these studies, a genomic HIV-1 tat expression vector, termed pgTAT, was used (Fig. 2A; Malim et al. 1988). The Rev protein not only activates env gene expression but simultaneously induces the expression of a truncated and easily assayed version of the Tat protein. In the pgTAT vector, the primary tat transcript initiates at the cytomegalovirus immediate early (CMV-IE) promoter cap site, extends through the two tat-coding exons, which are separated by intronic sequences corresponding to the overlapping env gene and HIV-1 RevRE, and terminates at a polyadenylation site provided by the genomic rat preproinsulin gene (Fig. 2A). Subsequently, this tat transcript is spliced at the indicated splice donor and acceptor sites to yield a cytoplasmic mRNA species that encodes the full-length, 86-amino-acid Tat protein. In the presence of the Rev protein, however, unspliced tat mRNAs appear in the cytoplasm (Malim et al. 1989), which, when translated, yield a truncated, but functional, 72-amino-acid form of the Tat protein. Production of this protein is due to termination at a conserved translation stop codon located downstream of the first tat-coding exon (see Fig. 2B, lanes 1 and 2). Tat expression plasmids containing different deletions within the intronic env region were cotransfected into COS cells with the Rex-I expression plasmid, pcREX-I. Anti-Tat immunoprecipitations of $\left[{ }^{35}\right.$ S $]$ cysteine radiolabeled COS cell extracts revealed that deletion of the HIV-1 RevRE in the pgATAT plasmid (Fig. 2A) abolished HTLV-I Rexdependent expression of the truncated 72-amino-acid Tat protein (Fig. 2B, lane 4). In contrast, deletion of intronic env sequences not involved in the HIV-1 RevRE 

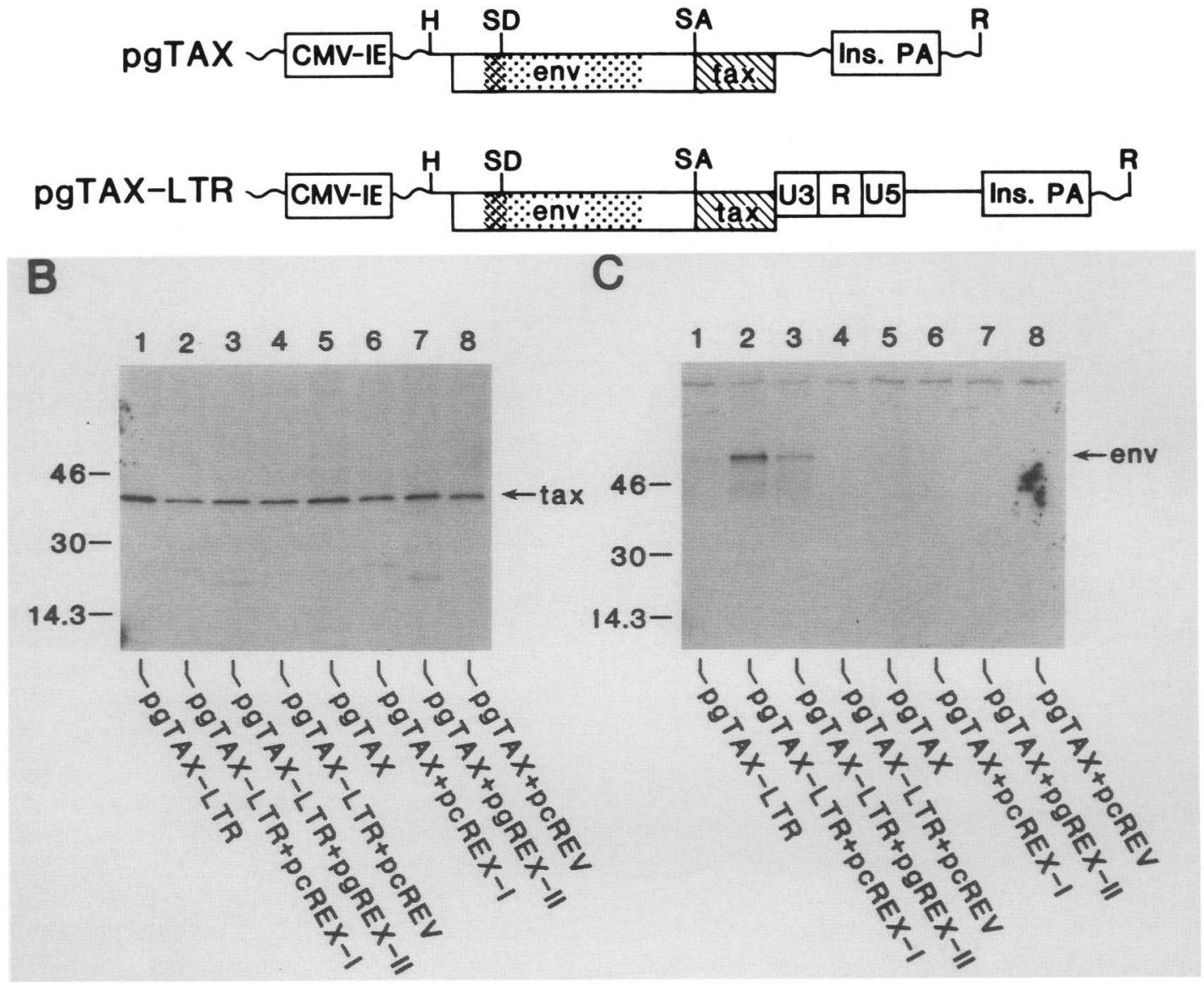

Figure 1. (A) Schematic summary of HTLV-I expression vectors, pgTAX, and pgTAX-LTR. Genomic restriction fragments of an HTLV-I proviral clone were inserted into the expression vector $\mathrm{pBCl} / \mathrm{CMV}$ (Cullen 1986), between the CMV-IE and the rat preproinsulin II gene RNA 3'-end processing and polyadenylation signals. The Tax protein-coding regions (hatched boxes) and the coding region for the HTLV-I envelope protein (stippled area) are shown. The first Tax-coding exon encodes only the initiator methionine, which is also the first amino acid of envelope protein. Tax protein is translated from mRNAs that are spliced between the indicated splice donor $(\mathrm{SD})$ and splice acceptor $(\mathrm{SA})$ sites, whereas the envelope protein is encoded by unspliced mRNA. The pgTAX-LTR construct also contains the coding exons for Tax and envelope but, in addition, the entire HTLV-I 3' LTR composed of the U3, R, and U5 regions as indicated. ( $B$ and $C$ ) HTLV-I env gene expression is induced by Rex-I and Rex-II, but not Rev, and requires the HTLV-I $3^{\prime}$ LTR. COS cells were transfected with the indicated plasmids and labeled metabolically $60 \mathrm{hr}$ later with [ $\left.{ }^{35} \mathrm{~S}\right] \mathrm{cysteine}$. The radiolabeled cell lysate was divided into two aliquots and immunoprecipitated with either anti-Tax antisera $(B)$ or the anti-HTLV-I envelope monoclonal antibody 0.5 Alpha ( $C$; Matsushita et al. 1986). Immunoprecipitated proteins were resolved by electrophoresis on discontinuous $10 \%$ SDS-polyacrylamide gels. The Tax and HTLV-I envelope proteins are indicated, as well as the migration of known molecular weight standards.

(KpnI/BglII; see Fig. 2A) had no effect on Rex-I action (Fig. 2B, lane 5). These findings suggest that the cis sequences required for Rex and Rev action in the HIV-1 system map to the RevRE. Whether different subregions within the RevRE are required for Rex and Rev action is presently under study.

\section{HTLV-I LTR confers Rex-I and Rex-II, but not ReV-1, responsiveness to the heterologous pgTAT expression vector}

Because the $3^{\prime}$ LTR of HTLV-I contains sequences that are required for Rex-I responsiveness in the homologous viral system (Fig. 1; Seiki et al. 1988), next we investi- gated whether Rex-I responsiveness could be conferred to the heterologous pgDTAT expression vector by the HTLV-I 3' LTR. An HTLV-I LTR fragment, which contained the entire $\mathrm{U} 3$ and $\mathrm{R}$ regions and a small portion of U5, was inserted in place of the 3' rat preproinsulin sequences (see Fig. 2A). When transfected into COS cells in the absence of Rex-I, this pg $\Delta$ TAT/LTR3' plasmid yielded only the 86-amino-acid form of the Tat protein (Fig. 3A, lane 1). However, transfection of $\operatorname{pg} \Delta \mathrm{TAT} /$ LTR3' with pcREX-I or pgREX-II resulted in the production of substantial amounts of the truncated 72-aminoacid Tat protein (Fig. 3A, lanes 2 and 3). In contrast, the HIV-1 Rev protein failed to induce the synthesis of the truncated 72-amino-acid Tat protein from the pg $\Delta \mathrm{TAT} /$ 
A

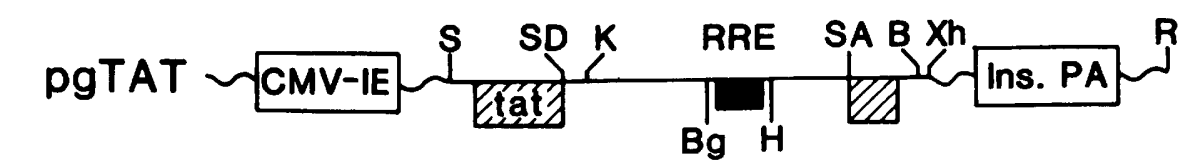

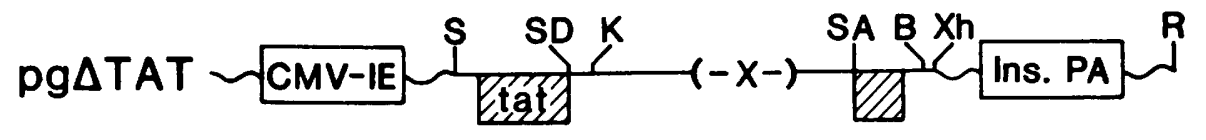

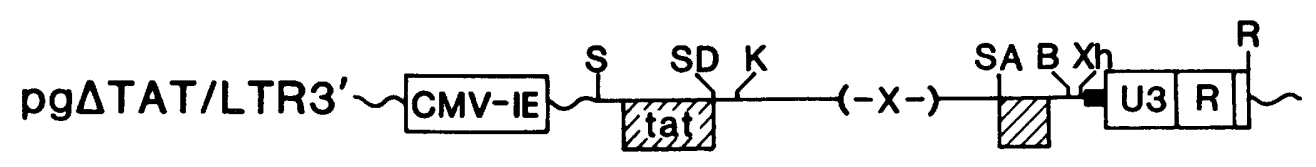

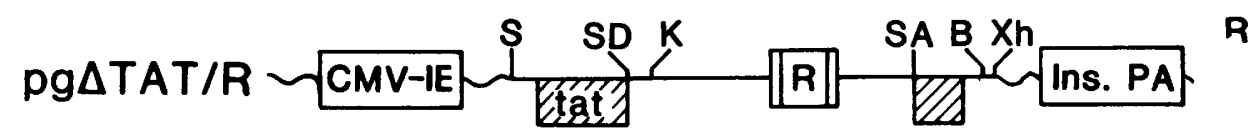

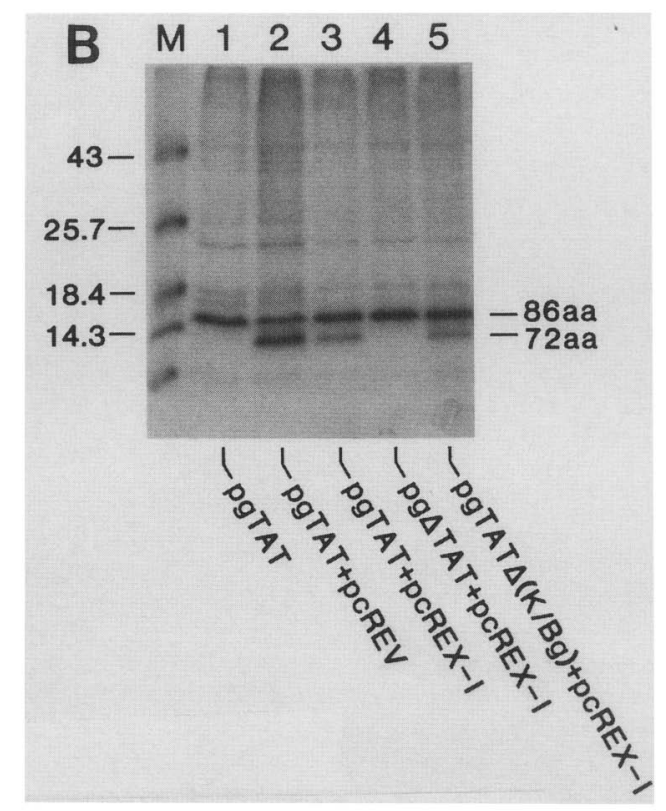

Figure 2. (A) Schematic summary of the HIV-1 pgTAT vector and derivatives of this plasmid lacking the HIV-1 RevRE (pg $\Delta$ TAT) and substituted with the HTLV-I RexRE (pgATAT/LTR3', pgATAT/R). The genomic tat expression vector, pgTAT, contains the two coding exons of the HIV-1 tat gene (hatched boxes) separated by intronic sequences that encode the overlapping env gene (Malim et al. 1988). The HIV-1 RevRE (black box) (RRE), was deleted in the pg $\Delta$ TAT construct by removal of the sequences between the $B g I I I(B g$ ) and HindIII (H) sites (Malim et al. 1989). The construct pgATAT/LTR3' was created by substituting the rat preproinsulin 3' processing and polyadenylation signals with an $\sim 700$-bp XhoI-HindIII fragment from the HTLV-I LTR. This HTLV-I LTR fragment contains all of the U3 and R regions, as well as the first $37 \mathrm{bp}$ of the U5. Requisite 3 '-end processing and polyadenylation signals are contained within this fragment (Seiki et al. 1983). The putative HTLV-I RexRE (R) was subcloned from the HTLV-I LTR using the polymerase chain reaction (Saiki et al. 1986, 1988) and was inserted into $\mathrm{pg} \Delta \mathrm{TAT}$ at the unique $\mathrm{XbaI}$ (X) site to create the pg $\Delta \mathrm{TAT} / \mathrm{R}$ plasmid. The $\mathrm{R}$ fragment was comprised of the final 41 nucleotides of $\mathrm{U} 3$, the entire $\mathrm{R}$ region, and the first 33 bases of the U5 region (see Fig. 4A). (SD) Splice donor; (SA) splice acceptor; (S) SalI; (K) KpnI; (B) BamHI; (R) EcoRI; (H) HindIII; (X) XbaI. (B) The HIV-1 Rev and HTLV-I Rex proteins act through the same HIV-1 response element. COS cells were transfected with the indicated plasmids, radiolabeled with ${ }^{35}$ S $]$ cysteine and immunoprecipitated with anti-Tat antibodies, as described previously (Malim et al. 1988, 1989; Rimsky et al. 1988). The full-length (86-amino-acid) and truncated (72-amino-acid) forms of the Tat protein derived from the spliced and unspliced tat mRNAs, respectively, are indicated. The migration of molecular weight protein standards is also shown (M). The pgTAT (Malim et al. 1988) or internally deleted versions of this vector [pg $\Delta$ TAT, pgTAT $\Delta(\mathrm{K} / \mathrm{Bg}$ ); see Fig. 2A; Malim et al. 1989] were cotransfected with the Rev (pcRev) (Malim et al. 1988) or Rex-I (pcRex-I) (Rimsky et al. 1988) expression vectors. The construct $\operatorname{pgTAT} \Delta(\mathrm{K} / \mathrm{Bg}$ ), (lane 5) contains a deletion of the tat intronic sequences between the KpnI and BglII restriction enzyme sites (see Fig. 2A) and thus retains the HIV-I RevRE (Malim et al. 1989). In contrast, pg $\Delta$ TAT (lane 4) contains a deletion between the BglII and HindIII sites and thus lacks the HIV-1 RevRE. 
LTR3' plasmid (Fig 3A, lane 4). As expected, the unmodified $\mathrm{pg} \Delta \mathrm{TAT}$ plasmid was not responsive to Rex (Fig. $3 \mathrm{~A}$, lane 5).

To explore these responses at the RNA level, S1 nuclease protection studies were performed with cytoplasmic RNAs isolated from COS cells transfected with the same plasmid combinations (Fig. 3C). Transfection of the pg $\Delta$ TAT/LTR3' plasmid in the absence of Rex yielded predominantly fully spliced tat mRNA encoding the complete Tat protein (Fig. 3C, lane 1). In contrast, considerable quantities of unspliced tat mRNA were detected in the presence of Rex-I or Rex-II (Fig. 3B, lanes 2 and 3). However, in agreement with the protein immunoprecipitations, the HIV-1 Rev protein failed to induce cytoplasmic expression of unspliced tat RNA following cotransfection with the pgATAT/LTR3' vector (Fig. 3B, lane 4). Together, these studies at the RNA and protein levels reveal that the HTLV-I $3^{\prime}$ LTR is sufficient to confer Rex-I and Rex-II responsiveness to a heterologous transcription unit. However, this element lacks the capacity to confer HIV-1 Rev responsiveness. These findings further underscore the nonreciprocal nature of complementation by the HTLV-I Rex and HIV-1 Rev proteins.

\section{HTLV-I RexRE corresponds to a putative RNA stem-loop structure}

Next we investigated whether the HTLV-I RexRE could be localized to a smaller region within the HTLV-I 3' LTR. Because the HIV-1 RevRE corresponds to an energetically stable stem-loop structure in the viral RNA

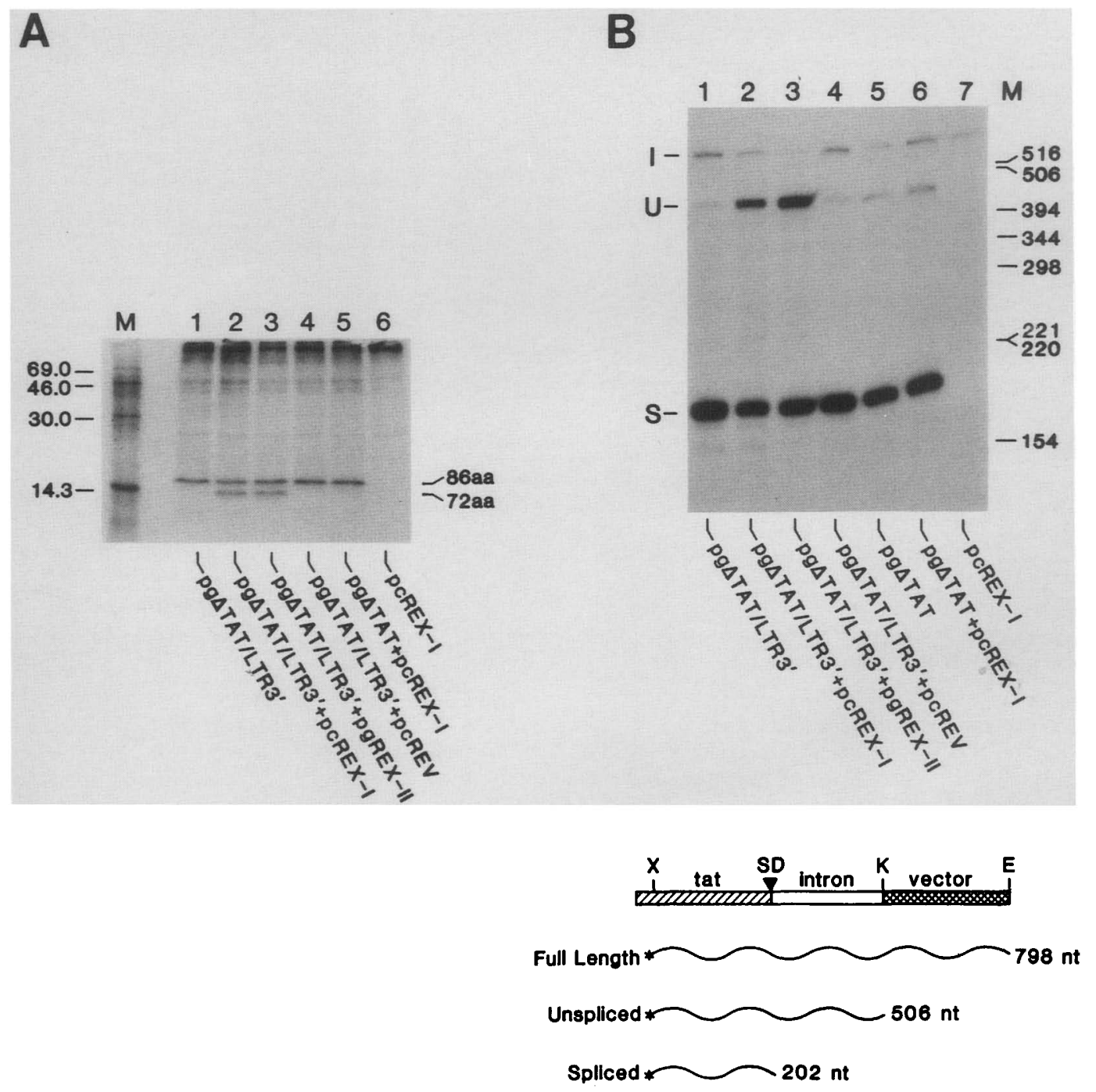

Figure 3. (A) The HTLV-I LTR confers Rex, but not Rev, responsiveness to an HIV-1 Tat expression vector. Anti-Tat immunoprecipitations were performed with radiolabeled extracts from COS cells transfected with the indicated plasmids (see Fig. 1). (B) S1 nuclease protection analysis of cytoplasmic RNA isolated from COS cells transfected with the indicated plasmids. A schematic diagram of the predicted size of the protected probe fragments is shown including input probe (I), 798 nucleotides; unspliced tat mRNA (U), 562 nucleotides; and spliced tat mRNA (S), 258 nucleotides. Two micrograms of cytoplasmic RNA was used for each analysis. Molecular weight markers used were an end-labeled HinfI restriction digest of pBR322. 
(Malim et al. 1989), we analyzed the HTLV-I LTR for a similar region of predicted secondary structure. These analyses revealed the presence of a very stable $(\Delta \mathrm{G}=-158.6 \mathrm{kcal} / \mathrm{mole})$ and highly significant $(-4.70$ S.D. units from the mean; $p<0.000001)$ predicted RNA stem-loop structure within a portion of the HTLV-I LTR (Fig. 4). This 279-nucleotide structure begins 2 nucleotides downstream of the AAUAAA polyadenylation signal (Proudfoot and Brownlee 1976) in U3 and extends through virtually the entire $\mathrm{R}$ region, ending 11 nucleotides upstream of the polyadenylation site.

In this regard, several groups have previously noted the exceptionally long $\mathrm{R}$ regions present in RNA transcripts of HTLV-I, HTLV-II, and the related bovine leukemia virus. It has also been proposed that these $\mathrm{R}$ regions may be looped out (Sagata et al. 1984; Sodroski et al. 1984b), thereby approximating the two distantly separated sequence elements required for efficient cleavage and polyadenylation of the primary viral mRNA transcripts (McDevitt et al. 1984; Sodofsky et al. 1985; for review, see Birnstiel et al. 1985; Gil and Proudfoot 1987). Specifically, looping out of the $\mathrm{R}$ region would position the $3^{\prime}$ GU boxes in U5 in correct spatial orientation with the AAUAAA motif present in U3 (see Fig. 4A). Of note, this looped-out region corresponds precisely to the predicted stem-loop structure (Fig. 4) and also maps within the boundaries of the region required for Rex responsiveness (Seiki et al. 1988). These findings raised the possibility that polyadenylation and Rex function might be linked. To investigate whether Rex action could be segregated from 3 '-end processing and polyadenylation, we inserted a DNA fragment corresponding to the 279-nucleotide predicted RNA stem-loop structure plus $2 \mathrm{nu}$ cleotides of 5 '-flanking sequences and 44 nucleotides of $3^{\prime}$-flanking sequences (see Fig. 4) into an intronic position in the $\operatorname{pg} \Delta \mathrm{TAT}$ vector, thus forming the $\mathrm{pg} \Delta \mathrm{TAT} / \mathrm{R}$ plasmid (see Fig. 2A). Although retaining the $3^{\prime} \mathrm{GU}$ boxes, this $\mathrm{R}$ region insert lacks the AAUAAA motif and therefore does not mediate polyadenylation. Appropriate cleavage and polyadenylation signals are provided in this plasmid by genomic rat preproinsulin II gene sequences positioned downstream of the second tat-coding exon. Anti-Tat immunoprecipitations in COS cells cotransfected with pgSTAT/R and the HTLV-I or HTLV-II Rex

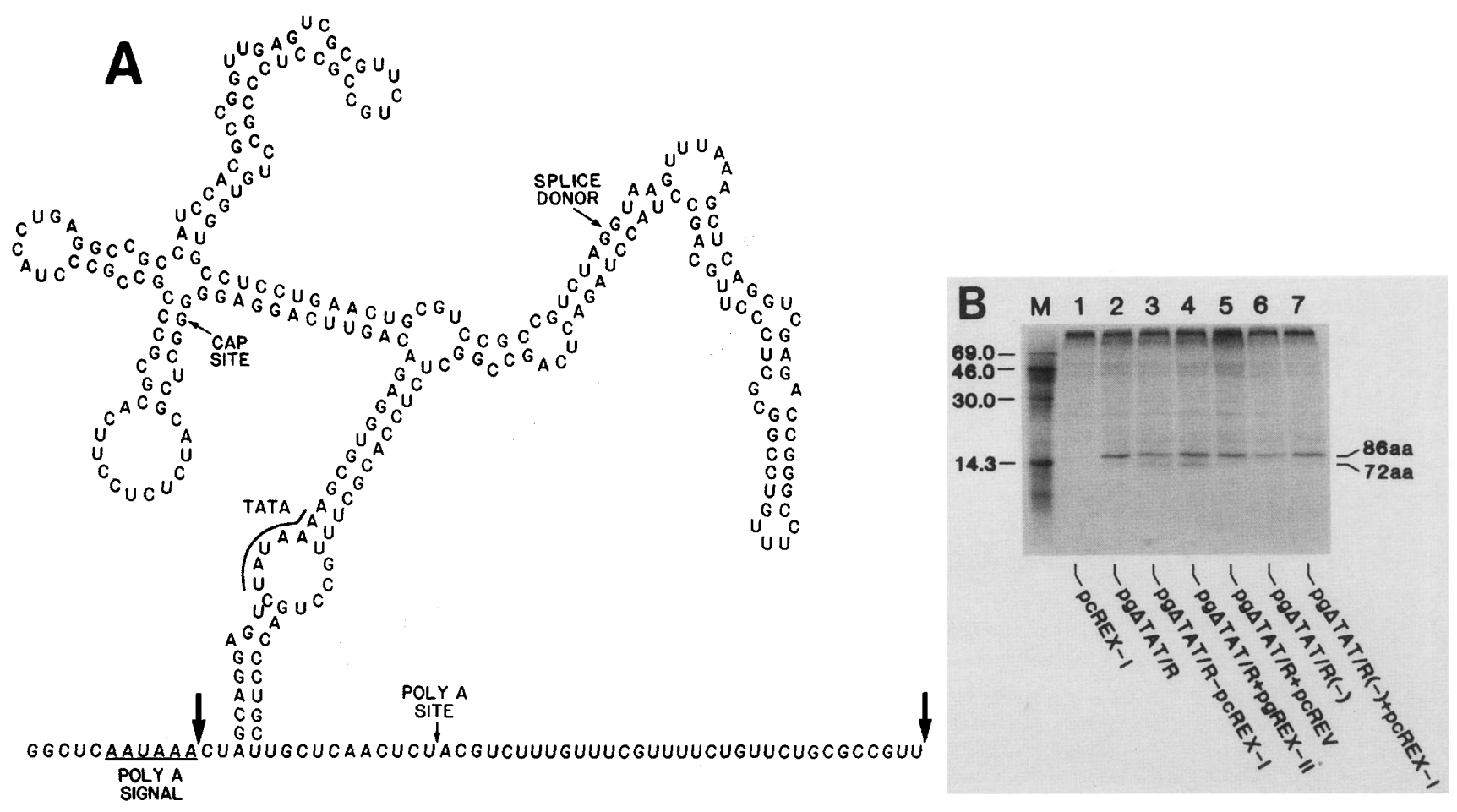

Figure 4. (A) Predicted secondary structure of the HTLV-I RexRE. Analysis of the HTLV-I LTR revealed an extremely stable $(\Delta \mathrm{G}=-158.6 \mathrm{kcal} / \mathrm{mole})$ and very significant (segment score in S.D. units $=-4.70)$ region of RNA secondary structure. This 279 nucleotide region encompases the 3 ' portion of the U3 region, including the TATA box and cap site, as well as most of the R region of the LTR. The $5^{\prime}$ boundary of the secondary structure is at map position 8613 (according to Seiki et al. 1983), 2 nucleotides downstream of the AAUAAA motif required for polyadenylation, whereas the $3^{\prime}$ boundary occurs 11 nucleotides prior to the end of the $\mathrm{R}$ region (map position 8868). The AAUAAA motif, TATA box, cap site, splice donor, and site of polyadenylation are indicated. The boundaries of the R fragment subsequently used for the construction of pgDTAT/R (see Fig. 2A) are indicated by the large arrows. (B) The HTLV-I RexRE confers HTLV-I and HTLV-II Rex responsiveness but not HIV-1 Rev responsiveness. Anti-Tat immunoprecipitations were performed on radiolabeled extracts from COS cells transfected with the indicated plasmids. The construct pg $\Delta$ TAT/R is depicted in Fig. 2A. The $\operatorname{pg} \Delta \mathrm{TAT} / \mathrm{R} /-$ ) contains the identical $\mathrm{R}$ fragment inserted in the antisense orientation at the unique $X b a \mathrm{I}$ site created in $\mathrm{pg} \Delta$ TAT. The 86-amino-acid and 72-amino-acid forms of the Tat protein are indicated. The migration of molecular weight markers (lane $M$ ) is shown. 
expression plasmids revealed that the $\mathrm{R}$ fragment alone was fully sufficient to confer Rex-I and Rex-II responsiveness (Fig. 4B, lanes 3 and 4). In agreement with the prior results, this $\mathrm{R}$ fragment failed to confer HIV-1 Rev responsiveness (Fig. 5, lane 5). This latter finding indicates that the inability of Rev to act on the HTLV-I RexRE is not a result of its location in the $3^{\prime}$ LTR, as this sequence is unable to confer Rev responsiveness, even when placed in an intronic position similar to the normal location of the HIV-1 RevRE. Insertion of the R fragment in the opposite orientation in $\operatorname{pg} \Delta \mathrm{TAT} / \mathrm{R} /-$ ) or downstream of the polyadenylation site abrogated Rex responsiveness (Fig. 4B, lanes 6 and 7; data not shown). Together, these results suggest that the HTLV-I RexRE, like the HIV-1 RevRE, corresponds to a complex RNA stem-loop structure whose function is orientation-dependent but position-independent and clearly separable from $3^{\prime}$ mRNA processing and polyadenylation.

Rex activates the transport of incompletely processed viral transcripts from the cell nucleus to the cytoplasm

Although the Rex protein promotes the expression of unspliced viral mRNAs in the cytoplasm, the mechanism by which these effects are produced remains unclear. Recent studies with the HIV-1 Rev protein suggest that this viral trans-regulator acts by inducing the transport of unspliced or singly spliced viral transcripts from the nucleus to the cytoplasm (Malim et al. 1988, 1989). Because Rex is able to complement Rev activity (Rimsky et al. 1988), it seemed likely that Rex might function in a similar manner. However, it has also been suggested that Rex may act by inhibiting splicing (Hidaka et al. 1988). We addressed this question by examining the distribution of spliced and unspliced tat mRNAs from the $\mathrm{pg} \Delta \mathrm{TAT} / \mathrm{R}$ vector in the nuclear and cytoplasmic compartments of transfected cells. In S1 nuclease protection assays, the levels of unspliced and spliced tat mRNAs in the nucleus proved comparable in the presence or absence of Rex (Fig. 5, lanes 1 and 3). The constitutive expression of such high levels of unspliced nuclear tat mRNA in the absence of Rex, in fact, argued against Rex acting as a primary regulator of splicing. In sharp contrast, although unspliced tat mRNAs were not detectable in the cytoplasm of transfected cells in the absence of Rex, these unspliced mRNAs were readily detected in the cytoplasm when Rex was cotransfected with the $\operatorname{pg} \Delta$ TAT/R expression vector (Fig. 5, lanes 2 and 4). These findings are most consistent with a model for Rex action involving its activation of the nuclear export of a constitutive pool of unspliced viral mRNAs containing the HTLV-I RexRE.

\section{Discussion}

The Rex and Rev proteins serve similar functions in the life cycles of the HTLV-I and HIV-1 retroviruses. Specifically, Rex and Rev induce the cytoplasmic expression of unspliced genomic mRNAs encoding the gag and pol gene products and the singly spliced transcripts en-

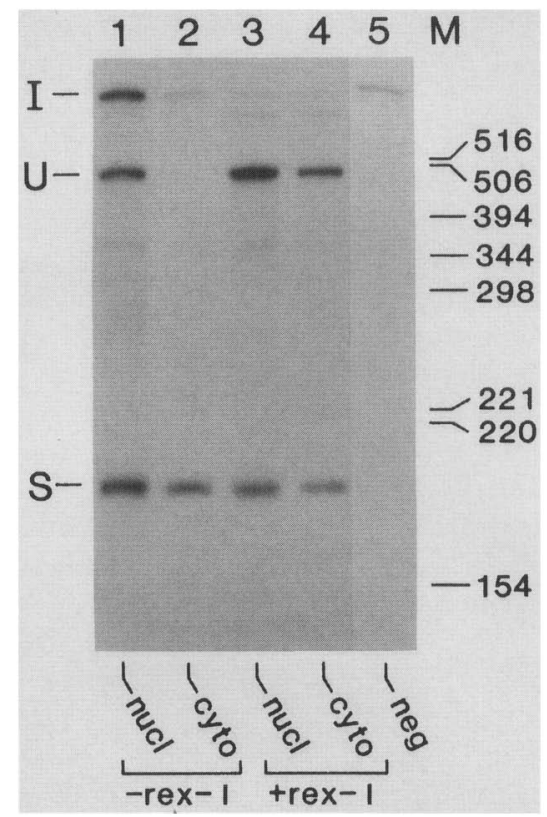

Figure 5. HTLV-I Rex activates the cytoplasmic expression of unspliced tat mRNAs. S1 nuclease analysis of fractionated nuclear and cytoplasmic tat mRNAs. COS cells were cotransfected with $\operatorname{pg} \Delta \mathrm{TAT} / \mathrm{R}$ in the absence (lanes 1 and 2) or presence (lanes 3 and 4) of the HTLV-I Rex expression vector pcRex-I. RNA analyzed in lane 5 was isolated from cells transfected with pcRex-I alone. Forty-eight hours after transfection, nuclear or cytoplasmic mRNAs were prepared (Chirgwin et al. 1979; Greenberg and Ziff 1984) and subjected to S1 nuclease analysis. Two micrograms of cytoplasmic (lanes 2 and 4), nuclear (lanes 1 and 3), or total cellular (lane 5) RNA was hybridized to the tat probe described in Fig. 3C. The input probe (I) and the positions of the $\mathrm{S} 1$ nuclease-resistant bands corresponding to unspliced $(\mathrm{U})$ and spliced $(\mathrm{S})$ tat $\mathrm{mRNAs}$ are indicated. Molecular weight markers (lane $M$ ) were an end-labeled HinfI restriction digestion of pBR322.

coding the envelope proteins. Both of these trans-regulators also function through related cis-sequence elements that appear to correspond to highly ordered RNA secondary structures (see also Malim et al. 1989). Notwithstanding these functional similarities, neither Rex-I nor Rev, nor their respective response elements shares any apparent sequence identity. This finding reflects the large evolutionary gulf that separates the $T$ cell leukemia and immunodeficiency viruses. Thus, it is striking that Rex-I is able to substitute for Rev and act through the HIV-1 RevRE. However, now we demonstrate that Rev is unable to complement the function of the HTLV-I Rex protein. This genetic nonreciprocity is most likely restricted by the RexRE, because Rev remains unable to complement Rex activity even when the RexRE is placed in an HIV context and in a location analogous to the HIV-1 RevRE. Although the precise biochemical basis for Rex and Rev action remains unknown, one possibility is that these proteins bind directly to their respective response elements. Alternatively, Rex and Rev may modulate the activity of various cellular factors that bind RNA transport. How- 
ever, the nonreciprocal nature of genetic complementation by the Rex and Rev proteins seems most easily explained by a model involving the direct interaction of these regulatory proteins with their viral response elements.

Ohta et al. (1988) suggested that the Rex-II protein of HTLV-II enhances the accumulation of only the unspliced genomic viral transcripts acting through a target sequence within the R-U5 region of the 5' LTR. Because this target sequence is spliced out of both env and tax-II/ rex-II transcripts, Ohta et al. argue that Rex-II only influences accumulation of unspliced mRNA. Although our experiments did not address this question directly, we did observe that Rex-II and Rex-I activitated HTLV-I env gene expression. Furthermore, Rex-II complemented Rex-I activity, acting through a common response element positioned in the U3-R region of the 3' LTR.

Function of the HTLV-I RexRE at the RNA level is supported by several independent lines of evidence. First, this element has the capacity to form a remarkably complex and stable stem-loop structure. Although the RexRE can be moved from a 3' exonic location to an intronic location with no effect on function, Rex activation is abrogated if this element is either positioned downstream of the polyadenylation site or inserted in the opposite orientation. These findings are most consistent with the recognition element being an RNA structure. The observations that the cis-acting RevRE also corresponds to a predicted RNA secondary structure (Malim et al. 1989) and that Rex is capable of acting through this element further strengthen this argument.

The RexRE was mapped initially to a larger region of the $3^{\prime}$ LTR that included the sequences necessary for mRNA cleavage and polyadenylation (Seiki et al. 1988). This finding raised the possibility that Rex function and polyadenylation might be linked. In this study we clearly exclude this possibility, demonstrating that Rex activation occurs when the response element is moved to an intronic position. Notwithstanding, the high degree of predicted secondary structure in the HTLV-I RexRE probably allows for appropriate approximation of the polyadenylation and cleavage signals that are so widely separated by the long $R$ regions characteristic of the HTLV family of viruses.

Although the precise mechanism of Rex action remains unclear, a primary role in the regulation of viral mRNA splicing seems unlikely. First, the HTLV-I RexRE is fully functional in both its natural exonic location at the $3^{\prime}$ terminus of viral mRNA and in an intronic position. Second, Seiki et al. (1988) demonstrated that partial Rex responsiveness can be conferred to an apparently unspliceable chloramphenicol acetyltransferase (CAT) expression plasmid by insertion of the HTLV-I LTR downstream of a CAT gene driven by an SV40 promoter. Finally, high constitutive levels of unspliced HIV-1 env mRNAs are apparent in the nuclei of cells in the absence of Rex. Rather than directly controlling splicing, Rex-I appears to act by inducing the transport of this constitutive pool of unspliced viral mRNA from the cell nucleus to the cytoplasm. Similar findings have been obtained with the HIV-1 Rev protein. Rex and Rev are both phosphoproteins that are localized primarily in the nucleoli of expressing cells (Cullen et al. 1988; Hauber et al. 1988; Siomi et al. 1988). It is possible that the nucleolus may serve as a gateway for Rex- and Revinduced export of these incompletely processed viral mRNAs that are normally excluded from the cytoplasm.

Finally, it is important to note that Rex not only induces the expression of the structural proteins necessary for virion assembly but also causes a reduction in the level of the regulatory proteins, including Tax (Hidaka et al. 1988; Rosenblatt et al. 1988). Because Tax is required for the activation of viral transcription, this would result in a dramatic reduction in the overall level of viral transcription and thereby diminish the expression of viral antigens. Thus, Rex may play a central role in the establishment and maintenance of viral latency. In contrast, as a result of differences in the splicing patterns of the HIV-1 transcripts, the HIV-1 Rev protein induces a truncated but biologically active form of the HIV-1 Tat protein (Malim et al. 1988). These differences may contribute to the relatively short latency period characteristic of HIV-1 infection compared with the very long latency encountered with HTLV-I.

\section{Materials and methods}

\section{Construction of viral expression vectors}

All of the vectors described in this paper were derived by insertion of viral genes between the CMV-IE promoter and rat preproinsulin II gene 3 '-end processing and polyadenylation signals in the pBC12/CMV expression vector (Cullen 1986). The pgTAX and pgTAX-LTR constructs (see Fig. 1A) were subcloned from the HTLV-I proviral clone CR-1, which was the generous gift of Dr. F. Wong-Staal (National Institutes of Health). Sequence coordinates of the restriction sites (according to Seiki et al. 1983) used for the constructions are indicated in brackets. pgTAX was created by insertion of a HindIII (5013)HindII (8557) fragment into $\mathrm{pBC12/CMV}$. The $5^{\prime}$ boundary of viral sequences cloned to create pgTAX-LTR was also the HindIII site (5013), whereas the 3 ' boundary extended through the entire $3^{\prime}$ LTR. This construct also contained $\cong 1 \mathrm{~kb}$ of human genomic DNA adjacent to the site of integration of the CR-1 provirus. The HTLV-I Rex and Tax proteins are encoded by the same spliced mRNA species but are translated in different reading frames (Seiki et al. 1985). Because Rex-I is translated using the first initiator methionine, Rex-I synthesis in the pgTAX and pgTAX-LTR expression vectors was eliminated by mutating the Rex-I initiator methionine, using SphI for restriction (5149) and clipping off the protruding ends. Construction of the genomic tat expression vector, pgTAT and its derivatives (Fig. 1B), as well as the HIV-1 Rev and HTLV-I Rex expression vectors was as described previously (Malim et al. 1988, 1989; Rimsky et al. 1988). The HTLV-II Rex expression plasmid pgRex-II was subcloned from an HTLV-II proviral clone /Chen et al. 1983) and contains the first and second coding exons of the Rex-II gene. This plasmid lacks the capacity to encode a functional HTLV-II Tax protein due to the introduction of a deletion downstream of the Rex stop codon (J. Kim, unpubl.). The construct pgATAT/LTR3' was created by excision of the rat preproinsulin II gene sequences between the $\mathrm{XhoI}(\mathrm{Xh})$ and EcoRI (R) restriction sites and insertion of an $\cong 700$-bp XhoIHindIII fragment from the HTLV-I LTR. The HindIII site was 
converted to an EcoRI site with linker-adaptors (New England Biolabs). The HTLV-I LTR fragment was derived from the plasmid pU3RI (Sodroski et al. 1984a) and contains all of the U3 and $R$ regions, as well as the first 37 bp of U5. The HTLV-I LTR fragment functionally replaces the rat preproinsulin gene sequences because it contains the requisite $3^{\prime}$-end processing and polyadenylation signals. The $R$ fragment was subcloned from the HTLV-I LTR using the polymerase chain reaction (Saiki et al. 1986, 1988). The $5^{\prime}$ boundary of $\mathrm{R}$ at map position 8613 , according to Seiki et al. (1985), was defined by a coding strand synthetic oligonucleotide, and the $3^{\prime}$ boundary at map position 8868 was delineated by a noncoding strand oligonucleotide. Both oligonucleotides were engineered with extensions that generated convenient restriction sites to facilitate insertion of the R fragment into the $\mathrm{XbaI}$ or EcoRI sites in pgDTAT (see Fig. 1). Gene amplification was performed as described by the supplier (Perkin-Elmer Cetus), except that the annealing temperature was increased to $50^{\circ} \mathrm{C}$.

\section{Cell culture and transfection}

Monkey kidney COS cells were maintained and transfected using DEAE-dextran and chloroquine, as described previously (Cullen 1986, 1987). For each experiment, the total amount of DNA transfected was $2.5 \mu \mathrm{g} / \mathrm{ml}$. If only one experimental expression vector was transfected, the DNA concentration was maintained at a constant level by cotransfecting the control $\mathrm{pBC} 12 / \mathrm{CMV} / \mathrm{IL}-2$ plasmid.

\section{Antisera and immunoprecipitation analysis}

The HTLV-I anti-Tax (Rimsky et al. 1988) and HIV-1 anti-Tat (Hauber et al. 1987) antisera were raised in rabbits using KLHconjugated synthetic peptides as immunogens. The human monoclonal antibody 0.5 Alpha (Matsushita et al. 1986) was used to immunoprecipitate the HTLV-I envelope precursor protein.

Immunoprecipitation of the HTLV-I Tax and envelope and HIV-1 Tat proteins was performed as described previously (Malim et al. 1988; Rimsky et al. 1988). Sixty hours after transfection, cells were starved in cysteine-free media for $1 \mathrm{hr}$ and then labeled biosynthetically with ${ }^{35} S$ ) cysteine (New England Nuclear and Amersham) for $2 \mathrm{hr}$. The cells were lysed in RIPA buffer (Cullen 1987), and the cleared protein lysate was incubated overnight at $4^{\circ} \mathrm{C}$ with the appropriate antiserum or antibody. Immune complexes were precipitated with Pansorbin (Calbiochem), washed, and resolved on discontinuous SDSpolyacrylamide gels. The immunoprecipitated radiolabeled proteins were visualized by autoradiography.

\section{RNA isolation and $S 1$ nuclease protection analysis}

Cytoplasmic and nuclear RNA were isolated from COS cells by isotonic lysis in the presence of $0.5 \%$ Nonidet P-40 (Chirgwin et al. 1979; Greenberg and Ziff 1984; Malim et al. 1988). S1 nuclease protection analyses were performed using $2 \mu \mathrm{g}$ of each RNA sample (Cullen 1986). The 798-nucleotide HIV-1 tat gene probe (see Fig. $2 \mathrm{C}$ ) was end-labeled at an XhoII site within the first coding exon. The probe extended beyond the splice donor site and was tagged with a pBR322 fragment to permit discrimination between the input probe (I) and the S1-protected bands corresponding to the unspliced (U, 506 nucleotides) and spliced (S, 202 nucleotides) RNA species (Malim et al. 1988).

\section{Computer analysis}

The distribution of significant RNA secondary structures in the HTLV-I LTR was calculated by processively analyzing seg- ments ranging in size from 30 to 300 nucleotides across the LTR. The optimal secondary structure was computed (Le et al. 1988) using the Cray Operating System of the Cray X-MP/24 computer and the energy rules of Salser (1977) and Cech et al. (1983)

\section{Acknowledgments}

We thank Dr. Hiroaki Mitsuya for the generous gift of the 0.5 alpha monoclonal antibody, Dr. Flossie Wong-Staal for the HTLV-I proviral pCR-1 plasmid, and Bonnie Kissell for expert assistance in the preparation of this manuscript. J.H.K. is a Pfizer postdoctoral fellow, M.D.D. is funded in part by a grant from the Association pour la Recherche sur le Cancer, Villejuif, France.

\section{References}

Barre-Sinoussi, F., J.C. Chermann, F. Rey, M.T. Nugeyre, S. Chamaret, J. Gruest, C. Dauguet, C. Axler-Blin, F. VezinetBrun, C. Rouzioux, W. Rozenbaum, and L. Montagnier. 1983. Isolation of a T-lymphotrophic retrovirus from a patient at risk for Acquired Immune Efficiency Syndrome (AIDS). Science 220: 868-871.

Birnstiel, M.L., M. Busslinger, and K. Strub. 1985. Transcription termination and $3^{\prime}$ processing: The end is in site! Cell 41: 349-359.

Burny, A., C. Bruck, H. Chantrenne, Y. Cleuter, D. Dekegel, J. Ghysdael, R. Kettman, M. Leclerq, J. Leunen, M. Mammerichk, and D. Portetelle. 1980. Bovine leukemia virus: Molecular biology and epidemiology. In Viral oncology, (ed. G. Klein), pp. 239-289. Raven Press, New York.

Cech, T.R., N.K. Tanner, I. Tinoco, B.R. Weir, M. Zuclker, and P.S. Perlman. 1983. Secondary structure of the Tetrahymena ribosomal RNA intervening sequences: Structural homology with fungal mitochondrial intervening sequences. Proc. Natl. Acad. Sci. 80: 3903-3907.

Chen, I.S.Y., J. McLaughlin, J.C. Gasson, S.C. Clarke, and D.W. Golde. 1983. Molecular characterization of genome of a novel human T-cell leukemia virus. Nature 305: 502-505.

Chirgwin, J.M., A.E. Przybyla, R.J. MacDonald, and W.J. Rulter. 1979. Isolation of biologically active ribonucleic acid from sources enriched in ribonuclease. Biochemistry 18: 52945299.

Cullen, B.R. 1986. Trans-activation of human immunodeficiency virus occurs via a bimodal mechanism. Cell 46: $973-$ 982.

- 1987. Use of eukaryotic expression technology in the functional analysis of cloned genes. Methods Enzymol. 71: $684-704$.

Cullen, B.R., J. Hauber, K. Campbell, J.G. Sodroski, W.A. Haseltine, and C.A. Rosen. 1988. Subcellular localization of the human immunodeficiency virus trans-acting art gene product. J. Virol. 62: 2498-2501.

Dayton, A.I., J.G. Sodroski, C.A. Rosen, W.C. Goh, and W.A. Haseltine. 1986. The trans-activator gene of the human Tcell lymphotropic virus type III is required for replication. Cell 44: 941-947.

Feinberg, M.B., R.F. Jarrett, A. Aldovini, R.C. Gallo, and F. Wong-Staal. 1986. HTLV-III expression and production involves complex regulation at the levels of splicing and translation of viral RNA. Cell 46: 807-817.

Felber, B.K., M. Hadzopoulou-Cladaras, C. Cladaras, T. Copeland, and G.N. Pavlakis. 1989. Rev protein of human immunodeficiency virus type 1 affects the stability and transport of the viral mRNA. Proc. Natl. Acad. Sci. 86: 1495-1499. 
Fisher, A.G., M.B. Feinberg, S.F. Josephs, M.E. Harper, L.M. Marselle, G. Reyes, M.A. Gonda, A. Aldovine, C. Deboule, R.C. Gallo, and F. Wong-Staal. 1986. The trans-activator gene of HTLV-III is essential for virus replication. Nature 320: $367-371$.

Gallo, R.C., S.Z. Salahuddin, M. Popovic, G.M. Shearer, M. Kaplan, B.F. Haynes, T.J. Palker, R. Redfield, J. Oleske, B. Safai, G. White, P. Foster, and P.D. Markham. 1984. Frequent detection and isolation of cytopathic retroviruses (HTLV-III) from patients with AIDS and at risk for AIDS. Science 224: 500-503.

Gessain, A., F. Barin, J.C. Vernant, O. Gout, L. Maurs, A. Calender, and G. de The. 1985. Antibodies to human T-lymphotropic virus type- 1 in patients with tropical spastic paraparesis. Lancet 2: 407-410.

Gil, A. and N.J. Proudfoot. 1987. Position-dependent sequence elements downstream of AAUAAA are required for efficient rabbit $\beta$-globin mRNA 3 ' end formation. Cell 49: 399-406.

Greenberg, M.E. and E.B. Ziff. 1984. Stimulation of 3T3 cells induces transcription of the c-fos proto-oncogene. Nature 311: $433-438$.

Hadzopoulou-Cladaras, M., B.K. Felber, C. Cladaras, A. Athanassopoulos, A. Tse, and G.N. Pavlakis. 1989. The rev (trs/ art) protein of human immunodeficiency virus type 1 affects viral mRNA and protein expression via a cis-acting sequence in the env region. J. Virol. 63: 1265-1274.

Hammarskjold, M.-L., J. Heimer, B. Hammarskjold, I., Sangwan, L. Albert, and D. Rekosh. 1989. Regulation of human immunodeficiency virus env gene product. $J$. Virol. 63: 1959-1966.

Hanaoka, M., K. Takatsuki and M. Shimoyama, eds. 1982. Adult T-cell leukemia and related disease. Gann Monogr. Cancer Res. 28: 1-237.

Hauber, J., M. Bouvier, M.H. Malim and B.R. Cullen. 1988. Phosphorylation of the rev gene product of human immunodeficiency virus type 1. I. Virol. 62: 4801-4804.

Hauber, J., A. Perkins, E.P. Heimer and B.R. Cullen. 1987.Trans-activation of human immunodeficiency virus gene expression is mediated by nuclear events. Proc. Natl. Acad. Sci. 84: 6364-6368.

Hidaka, M., J. Inoue, M. Yoshida, and M. Seiki. 1988. Post-transcriptional regulator (rex) of HTLV-1 initiates expression of viral structural proteins but suppresses expression of regulatory proteins. EMBO I. 7: 519-523.

Inoue, J.-I., M. Yoshida, and M. Seiki. 1987. Transcriptional $\left(\mathrm{p} 40^{\mathrm{x}}\right)$ and post-transcriptional $\left(\mathrm{p}^{2} 7^{\mathrm{x}-111}\right)$ regulators are required for the genes. Proc. Natl. Acad. Sci. 84: 3653-3657.

Inoue, J., M. Seiki, T. Taniguchi, S. Tsuru, and M. Yoshida. 1986. Induction of interleukin 2 receptor gene expression by p40 encoded by human T-cell leukemia virus type I. EMBO J. 5: 2883-2888.

Kalyanaraman, V.S., M.G. Sarngadharan, M. Robert-Guroff, I. Miyoshi, D. Golde, and R.C. Gallo. 1982. A new subtype of human T-cell leukemia virus (HTLV-II) associated with a variant of hairy cell leukemia. Science 218: 571-573.

Le, S.-Y., J.-H. Chen, M.J. Braun, M.A. Gonda, and J.V. Maizel. 1988. Stability of RNA stem-loop structure and distribution of non-random structure in the human immunodeficiency virus (HIV-1). Nucleic Acids Res. 16: 5153-5168.

Malim, M.H., J. Hauber, R. Fenrick, and B.R. Cullen. 1988. Immunodeficiency virus rev trans-activator modulates the activity of the viral regulatory genes. Nature 335: 181-183.

Malim, M.H., J. Hauber, S.-Y. Le, J.V. Maizel, and B.R. Cullen. 1989. The HIV-1 rev trans-activator acts through a structured target sequence to activate nuclear export of unspliced viral mRNA. Nature 338: 254-257.

Matsushita, S., M. Robert-Guroff, J. Trepel, J. Cossman, H. Mitsuya, and S. Broder. 1986. Human monoclonal antibody directed against an envelope glycoprotein of human T-cell leukemia virus type I. Proc. Natl. Acad. Sci. 83: 2672-2676.

McDevitt, M.A., M.J. Imperiale, H. Ali, and J.R. Nevins. 1984. Requirement of a downstream sequence for generation of a poly(A) addition site. Cell 37: 993-999.

Ohta, M., H. Nyunoya, H. Tanaka, T. Okamoto, T. Akaji, and K. Shimotohno. 1988. Identification of a cis-regulatory element involved in accumulation of human T-cell leukemia virus type II genomic mRNA. J. Virol. 62: 4445-4451.

Osame, M., K. Usuku, N. Jjichi, H. Amitani, A. Igata, M. Matsumoto, and H. Tara. 1986. HTLV-I associated myelopathy, a new clinical entity. Lancet 1: 1031-1032.

Poiesz, B.J., F.W. Ruscetti, M.S. Reitz, V.S. Kalyanaraman, and R.C. Gallo. 1981. Isolation of a new type C retrovirus (HTLV) in primary uncultured cells of a patient with Sezary T-cell leukemia. Nature 294: 268-271.

Poiesz, B.J., F.W. Ruscetti, A.F. Gazdar, P.A. Bunn, J.D. Mihna, and R.C. Gallo. 1980. Detection and isolation of type C retrovirus particles from fresh cultured lymphocytes of a patient with cutaneous T-cell lymphoma. Proc. Natl. Acad. Sci. 77: 7415-7419.

Popovic, M., M.G. Sarngadharan, E. Read, and R.C. Gallo. 1984. Detection, isolation and continuous production of cytopathic retroviruses (HTLV-III) from patients with AIDS and pre-AIDS. Science 224: 497-500.

Proudfoot, N.J. and G.G. Brownlee. 1976. 3' Non-coding region sequences in eukaryotic messenger RNA. Nature 263: 211 214.

Rimsky, L., J. Hauber, M. Dukovich, M.H. Malim, A. Langlois, B.R. Cullen, and W.C. Greene. 1988. Functional replacement of the HIV-1 Rev protein by the HTLV-I Rex protein. Nature 335: 738-740.

Rosen, C.A., E. Terwilliger, A. Dayton, J.G. Sodroski, and W.A. Haseltine. 1988. Intragenic cis-acting art gene-responsive sequences of the human immunodeficiency virus. Proc. Natl. Acad. Sci. 85: 2071-2075.

Rosenblatt, J.D., A.J. Cann, D.W. Golde, and I.S.Y. Chen. 1986. Structure and function of the human T-cell leukemia virus II genome. Cancer Rev. 1: 115-135.

Rosenblatt, J.D., A.J. Cann, D.J. Slamon, I.S. Smalberg, N.P. Shah, J. Fujii, W. Wachsmau, and I.S.Y. Chen. 1988. HTLV-II Trans-activation is regulated by the overlapping tax/rex nonstructural genes. Science 240: 916-919.

Sadaie, M.R., T. Benter, and F. Wong-Staal. 1988. Site-directed mutagenesis of two trans-regulatory genes (tat-III, trs) of HIV-1. Science 239: 910-914.

Sagata, N., T. Yasunaga, Y. Ogawa, J. Tsuzuku-Kawamura, and Y. Ikawa. 1984. Bovine leukemia virus: Unique structural features of its long terminal repeats and its evolutionary relationship to human T-cell leukemia virus. Proc. Natl. Acad. Sci. 81: 4741-4745.

Sagata, N., T. Yasunaga, J. Tsuzuku-Kawamura, K. Ohishi, Y. Ogawa, and Y. Ikawa. 1985. Complete nucleotide sequence of the genome of bovine leukemia virus: Its evolutionary relationship to other retroviruses. Proc. Natl. Acad. Sci. 82: $677-681$.

Saiki, R.K., T.L. Bugawan, G.T. Horn, K.B. Mullis and H.A. Erlich. 1986. Analysis of enzymatically amplified $\beta$-globin and HLA-DQaDNA with allele-specific oligonucleotide probes. Nature 324: 163-166.

Saiki, R.K., D.H. Gelfand, S. Stoffel, S.J. Scharf, R. Higuchi, G.J. Horn, K.B. Mullis, and H.A. Erlich. 1988. Primer-directed 
Hanly et al.

enzymatic amplification of DNA with a thermostable DNA polymerase. Science 239: 487-491.

Salser, W. 1977. Globin mRNA sequences analysis of base pairing and evolutionary implications. Cold Spring Harbor Symp. Quant. Biol. 42: 985-1002.

Sarngadharan, M.G., M. Popovic, L. Bruch, J. Schupbach, and R.C. Gallo. 1984. Antibodies reactive with human T-lymphotropic retroviruses (HTLV-III) in the serum of patients with AIDS. Science 224: 506-508.

Seiki, M., S. Hattori, Y. Hirayama, and M. Yoshida. 1983. Human adult T-cell leukemia virus: Complete nucleotide sequence of the provirus genome integrated in leukemia cell DNA. Proc. Natl. Acad. Sci. 80: 3618-3622.

Seiki, M., A. Hikikoshi, T. Taniguchi, and M. Yoshida. 1985. Expression of the pX gene of HTLV-I: General splicing mechanism in the HTLV family. Science 227: 1227-1229.

Seiki, M., J.-I. Inoue, M. Hidaka, and M. Yoshida. 1988. Two cis-acting elements responsible for post-transcriptional trans-regulation of gene expression of human T-cell leukemia virus type I. Proc. Natl. Acad. Sci. 85: 7124-7128.

Shimotohno, K., W. Wachsman, Y. Takahashi, D.W. Golde, M. Miwa, T. Sugimura, and I.S.Y. Chen. 1984. Nucleotide sequence of the 3 ' region of an infectious human T-cell leukemia vinus type II genome. Proc. Natl. Acad. Sci. 81: 6657-6661.

Siegal, F.P., C. Lopez, G.S. Hammer, A.E. Brown, S.J. Komfeld, J. Gold, J. Hassett, S.Z. Hirschman, S. CunninghamRundles, and D. Armstrong. 1981. Severe acquired immunodeficiency in male homosexuals, manifested by chronic perianal ulcerative herpes simplex lesions. N. Engl. I. Med. 305: 1439-1444.

Siomi, H., H. Shida, S. Hyun Nam, T. Nosaka, M. Maki, and M. Hatanaka. 1988. Sequence requirements for nucleolar localization of human T-cell leukemia virus type $1 \mathrm{pX}$ protein which regulates viral RNA processing. Cell 55: 197-209.

Sodofsky, M., S. Connelly, J.L. Manley, and J.C. Alwine. 1985. Identification of a sequence element on the 3 '-side of AAUAAA which is necessary for SV40 late mRNA $3^{\prime}$-end processing. Mol. Cell. Biol. 5: 2713-2719.

Sodroski, J.G., C.A. Rosen, and W.A. Haseltine. 1984a. Transacting transcriptional activation of the long terminal repeat of Human $\mathrm{T}$ Lymphotrophic Viruses in infected cells. Science 225: 381-385.

Sodroski, J., W.C. Goh, C. Rosen, A. Dayton, E. Terwilliger, and W. Haseltine. 1986. A second post-transcriptional trans-activator gene required for HTLV-III replication. Nature 321: $412-417$.

Sodroski, J., C. Rosen, F. Wong-Staal, S.Z. Salahuddin, M. Popovic, S. Arya, R.C. Gallo, and W.A. Haseltine. 1985. Transacting transcriptional regulation of human T-cell leukemia virus type III long terminal repeat. Science 227: 171-173.

Sodroski, J., M. Trus, D. Perkins, R. Patarca, F. Wong-Staal, E. Gelmann, R. Gallo, and W.A. Haseltine. 1984b. Repetitive structure in the long-terminal-repeat element of a type II human T-cell leukemia virus. Proc. Natl. Acad. Sci. 81: 4617-4621.

Terwilliger, E.R. Burghoff, R. Sia, J. Sodroski, W.A. Haseltine, and C. Rosen. 1988. The art gene product of human immunodeficiency virus is required for replication. J. Virol. 62: 655-658.

Wano, Y., M. Feinberg, J.B. Hosking, H. Bogerd, and W.C. Greene. 1988. Stable expression of the tax gene of type I human T-cell leukemia virus in human T-cells activates specific cellular genes involved in growth. Proc. Natl. Acad. Sci. 85: 9733-9737.

Yoshida, M., I. Miyoshi, and Y. Hinuma. 1982. Isolation and characterization of retrovirus from cell lines of human adult T-cell leukemia and its implication in the disease. Proc. Natl. Acad. Sci. 79: 2031-2035.

Yoshida, M. and M. Seiki. 1987. Recent advances in the molecular biology of HTLV-I: trans-activation of viral and cellular genes. Annu. Rev. Immunol. 5: 541-559. 


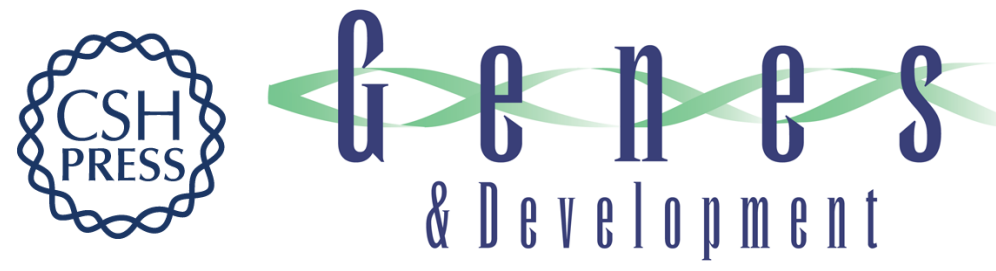

\section{Comparative analysis of the HTLV-I Rex and HIV-1 Rev trans-regulatory proteins and their RNA response elements.}

S M Hanly, L T Rimsky, M H Malim, et al.

Genes Dev. 1989, 3:

Access the most recent version at doi:10.1101/gad.3.10.1534

References This article cites 61 articles, 32 of which can be accessed free at:

http://genesdev.cshlp.org/content/3/10/1534.full.html\#ref-list-1

License

Email Alerting

Service

Receive free email alerts when new articles cite this article - sign up in the box at the top right corner of the article or click here.

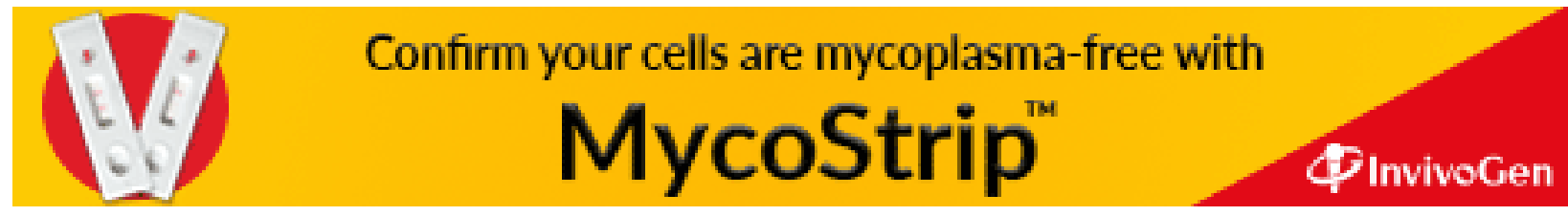

